\title{
A paisagem na perspectiva tempo-espaço-máquina
}

\section{The landscape in the time-space-machine perspective}

Beatriz Basile da Silva Rauscher Artista e professora do Curso de Graduação em Artes Visuais e do Programa de Pós-Graduação em Artes e da Universidade Federal de Uberlândia (UFU), líder do grupo de pesquisa Poéticas da Imagem UFU/CNPq beatriz.rauscher@gmail.com ORCID: https://orcid.org/0000-0002-1969-2137

\section{RESUMO:}

A abordagem da representação da natureza, operada pela série de fotografias Paisagens do asfalto, é observada na perspectiva da experiência da viagem mediada pela técnica, e nas implicações das relações tempoespaço-máquina, presentes nas imagens. As questões teóricas se concentram nas ideias da fotodinâmica futurista (BRAGAGLIA, 1980); na crítica do declínio da experiência do espaço gerada pela telepresença (VIRILIO, 1989, 1993) e na reflexão sobre as implicações do artifício técnico e do código na paisagem (CAUQUELIN, 2007; FLUSSER, 2002, 2008).

Palavras-chave: Paisagem. Fotografia. Imagem técnica.

\section{ABSTRACT:}

The approach of the representation of nature operated by the photo series Landscapes of the road is observed from the perspective of the trip experience mediated by technique and through the relations time-space-machine. The theoretical questions focus on the ideas of futuristic photodynamics (BRAGAGLIA, 1980), on the criticism of the decline of the space experience generated by telepresence (VIRILIO, 1989, 1993), and theoretical reflection on the implications of technical artifice and code in landscape (CAUQUELIN, 2007; FLUSSER, 2002, 2008).

Keywords: Landscape. Photography. Technical image.

RAUSCHER, Beatriz Basile da Silva. A paisagem na perspectiva tempo-espaço-máquina. PóS:Revista do Programa de Pós-graduação em Artes da EBA/UFMG. v.9, n.17: mai. 2019. 
Artigo recebido em $21 / 11 / 2018$

Artigo aprovado em 10/03/2019

\section{Um lugar de partida}

Este artigo está ancorado em minha produção artística, especificamente em um conjunto de imagens fotográficas tomadas em viagens de carro, intitulado Paisagens do asfalto. Não se trata de um exame sobre minha produção com o fim de legitimá-la, mas do entendimento que a prática pode levar o artista a lugares e inquietações teóricas, diferentes da análise que faria o teórico ou o historiador da arte.

As fotografias reunidas na série Paisagens do asfalto foram recolhidas em estradas que cortam o estado de São Paulo, entre elas, a Rodovia Anhanguera, que descreve uma topografia muito regular da capital até o estado de Minas Gerais. Ali, a rodovia Anhanguera se liga à BR 050, estrada federal que corta o Triângulo Mineiro até o estado de Goiás.
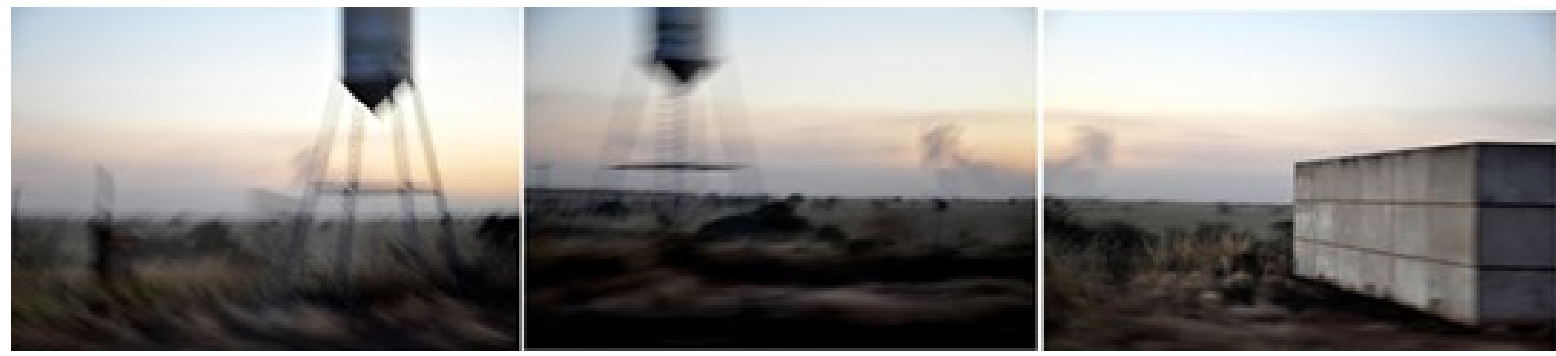

Imagem 1 - BR50 Sul

Nota: 3 fotografias, (impressão em metacrilato; - três peças) dimensão: 057 x 037,8 cm (cada) 2001-2013

Fonte: nossa autoria.

O nome da rodovia faz referência ao explorador Anhanguera, e seu trajeto pelo centro do país no século 18. Ao longo dos seus 440 quilômetros, estão várias cidades do interior paulista e grandes extensões de áreas agrícolas. As terras

RAUSCHER, Beatriz Basile da Silva. A paisagem na perspectiva tempo-espaço-máquina.

PóS:Revista do Programa de Pós-graduação em Artes da EBA/UFMG. v.9, n.17: mai. 2019.

Disponivel em <https://eba.ufmg.br/revistapos> 
cortadas por ela, tomadas pelo cultivo de cana e grãos, descrevem uma geografia muito plana e uniforme. Assim, a viagem transforma-se em uma experiência de monotonia hipnótica. Que espécie de natureza é esta que se mostra pela janela do carro? O resultado de intervenções sucessivas, pelo homem e pela máquina, faz-nos indagar sobre o que resta da natureza nessa paisagem. É possível resgatá-la pelo artifício, reinventá-la?

A série abordada neste texto permite indagar sobre a experiência da viagem e sobre a representação da natureza atravessada pela máquina. Coloca-se em questão a identificação das imagens com aquilo que convencionamos chamar de paisagem. São imagens que nos dizem das viagens, dos trânsitos e dos deslocamentos. Colabora com isso o uso da técnica, que recorre à subversão do programa do aparelho por meio da manipulação das variáveis de espaço, tempo, luz e velocidade, buscando operar no limite para obter não a boa imagem, mas uma imagem imperfeita.

Assim, este texto trata de uma possível leitura elaborada da série de imagens aqui relacionadas, segundo uma concepção de paisagem, que implica tempo, espaço e máquina. Na primeira parte, o texto apresenta a dimensão operatória do trabalho, apontando como a técnica pode produzir diferentes visões, experiências e abordagens do espaço-tempo. Para tanto, apresentam-se questionamentos teóricos relacionados à temporalidade: (1) a noção de impermanência, pela desmaterialização da imagem, ocasionada pela preponderância do fluxo e do passageiro; (2) a ideia de intermitência (AUMONT, 2004) que a sequência temporal apresentada nesses trabalhos propõe.

A seguir observa-se a espacialidade das imagens (como o rastro de luz, que determina a desmaterialização dos planos na tomada fotográfica e gera a qualidade de imagem), que pode ser aproximada das imagens que interessavam aos artistas futuristas. Isso se dá tanto pela desconstrução da representação do espaço quanto pela evocação da máquina e da velocidade. Para a discussão e atualização das questões que concernem ao sentido espacial da trajetória, 
contrapõem-se as ideias oriundas da fotodinâmica futurista e as críticas contemporâneas das condições espaço-tempo real e virtual: síntese de trajetória e estados interestáticos em Bragaglia (1980), por um lado, e perda da narrativa de trajeto e declínio da experiência do espaço, em Virilio (1993), por outro.

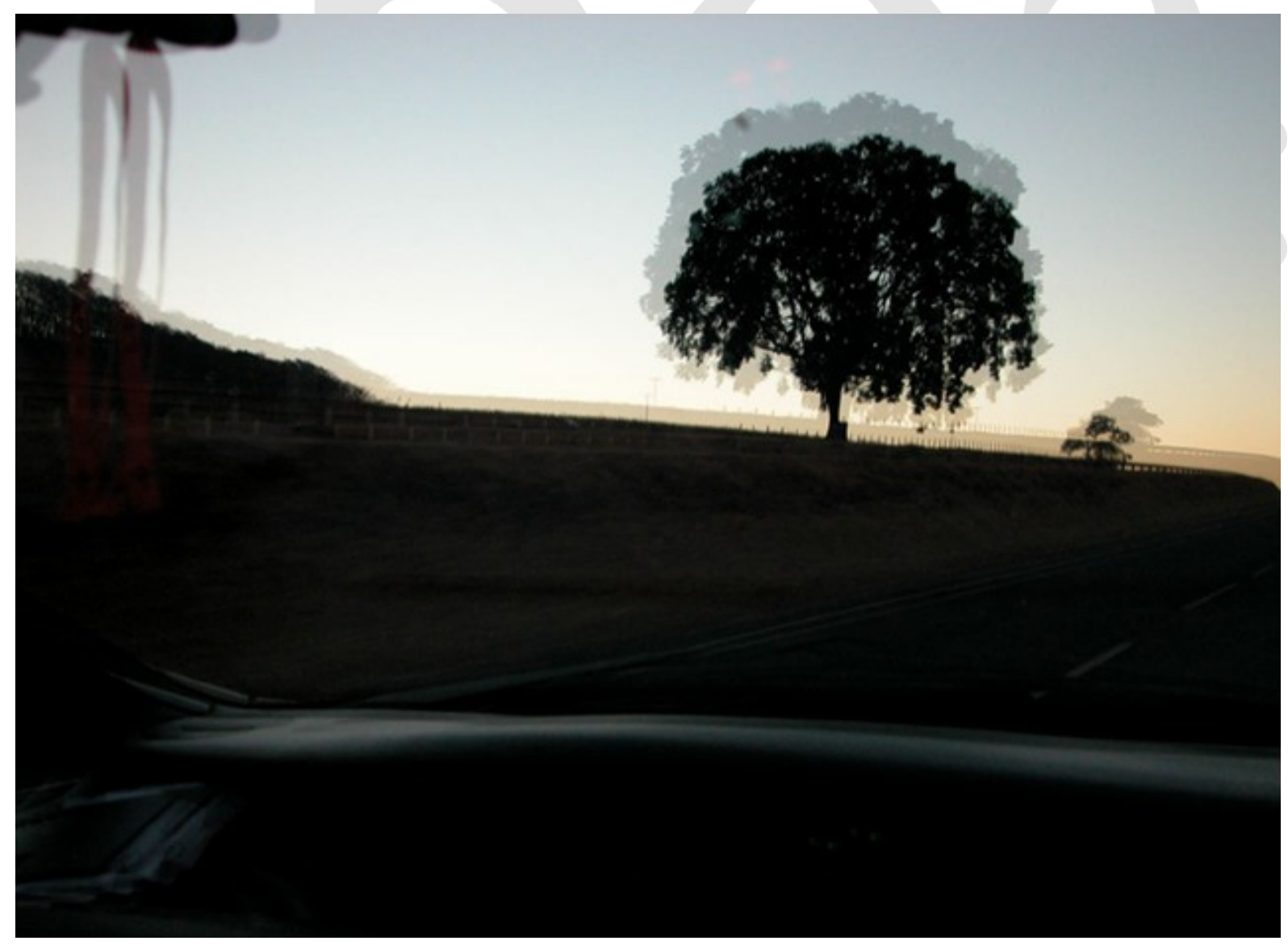

Imagem 2 - one way trip - 2009-2017

Nota: fotografia; impressão em papel 100\% algodão; 30 × 23 cm. .

Fonte: nossa autoria.

Na última parte, Dubois (1993), Cauquelin (2007) e Flusser (2008) tornam possível a reflexão sobre as dimensões do código e do artifício técnico presentes nas imagens, e sua influência na experiência e percepção da paisagem.

RAUSCHER, Beatriz Basile da Silva. A paisagem na perspectiva tempo-espaço-máquina. PóS:Revista do Programa de Pós-graduação em Artes da EBA/UFMG. v.9, n.17: mai. 2019. Disponível em <https://eba.ufmg.br/revistapos> 


\section{A experiência espaço-tempo: paisagem e fotografia}

O termo paisagem, na Geografia ${ }^{1}$, a rigor, refere-se à porção da configuração territorial que é possível abarcar com a visão. O entendimento de paisagem, nesse campo, aponta para as formas que exprimem as heranças das relações entre o homem e a natureza. Ela é o conjunto de elementos naturais e artificiais que fisicamente caracterizam uma área.

As práticas artísticas, por sua vez, revelam diferentes modos de sensibilidade em relação ao espaço e à natureza. Nelas se inserem o que se convencionou chamar de paisagem no campo da Arte. Existem artistas que, conscientes da degradação do mundo natural, estão em busca de captar, pela arte, o que tem sido negado ao mundo. Assim, a paisagem que vemos na arte, aparece como "resultado de uma reconstrução e também de uma estetização". ${ }^{2}$ Para outro tipo de sensibilidade, o que importa é a natureza como potência de transformação. São as obras que atuam diretamente sobre o lugar, a matéria, o solo e os elementos que os constitui: areia, argila, pedras etc. Para o teórico Gilles Tiberghien, essas duas formas de sensibilidade não são contraditórias e podem coexistir nas obras de um mesmo artista.

Paisagens do asfalto é um trabalho em processo. Enquanto material bruto, reúne milhares de fotografias tiradas em viagens de carro, desde os anos de 2008. Os gestos técnicos que articulam os conceitos do trabalho são: as tomadas do interior do veículo; através do anteparo do vidro; sob interferências do próprio deslocamento (velocidade e trepidação); sob interferência de diferentes luminosidades - Imagem 2; tomadas sucessivas e baixa velocidade do obturador. Quanto às operações sobre as fotografias digitais, estão combinações, panoramas-sequências - Imagens 1 e 5, ampliações em diferentes tamanhos e diferentes suportes, articulação de modos de oferecimento, animações, diaporamas, projeções, vídeosequências e vídeo interativo - Imagens 3 e 4 . Os problemas principais que esses

RAUSCHER, Beatriz Basile da Silva. A paisagem na perspectiva tempo-espaço-máquina. PóS:Revista do Programa de Pós-graduação em Artes da EBA/UFMG. v.9, n.17: mai. 2019. Disponivel em <https://eba.ufmg.br/revistapos> 
trabalhos abordam são: a inscrição do homem na natureza, e as ideias de trânsito, de tempo, de deslocamento nas experiências das viagens em territórios contemporâneos.

Considerando a dimensão da experiência, que se reflete no objeto de arte, observa-se de que modo operações técnicas e arranjos formais podem introduzir as noções de tempo na imagem estática. Sem querer reduzir a fotografia a um simples protocolo da experiência, considera-se, antes que seu estatuto de documento, sua transcendência, e o ato fotográfico, a um só tempo, espacial e temporal.
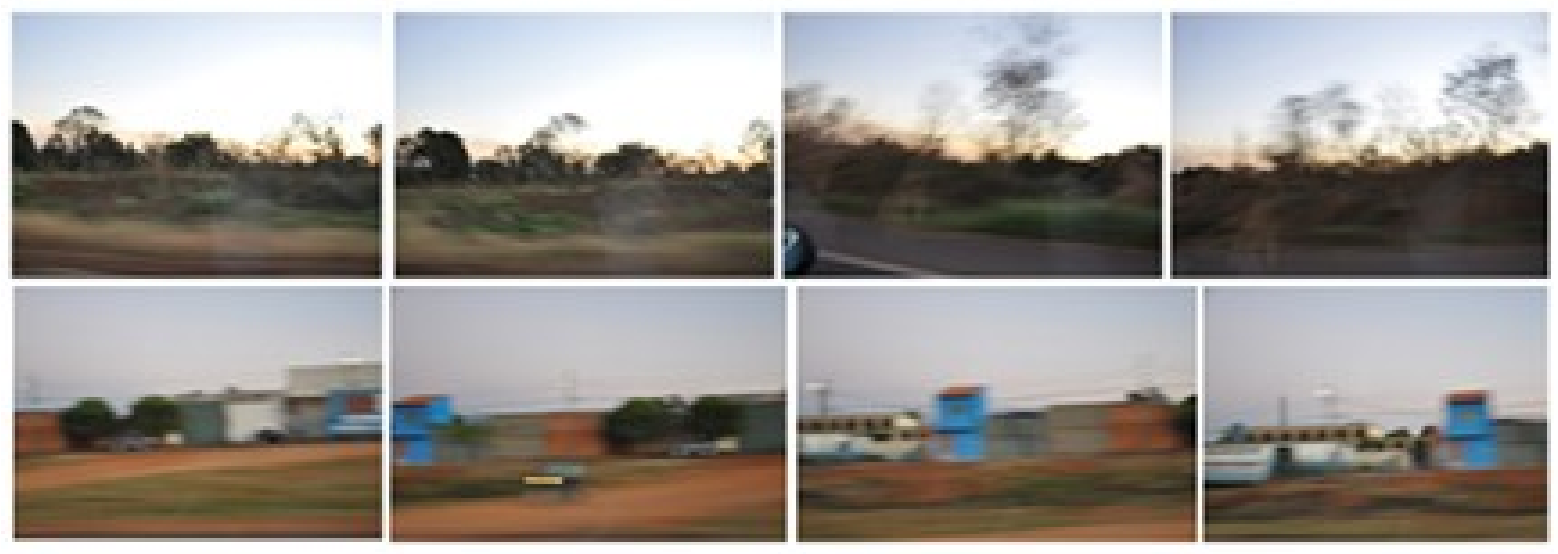

Imagem 3 - road blues, diaporama sonoro, 2010-2014

As fotografias tomadas em deslocamento, pouco nítidas, vistas de passagem, apontam sua inclinação para o sentido de impermanência. A velocidade, mais que a medida do tempo do deslocamento, é uma forma de olhar o mundo. "A velocidade transforma a paisagem, faz com que o mundo se desmanche, flua, como uma onda". ${ }^{3}$ Quando passamos em velocidade pelas coisas, elas se transformam em espectros, quase não as vemos, dizemos que elas desaparecem rapidamente. Podemos supor que, nessas condições, à contemplação da paisagem justapõe-se a impressão de desaparecimento.

RAUSCHER, Beatriz Basile da Silva. A paisagem na perspectiva tempo-espaço-máquina. PóS:Revista do Programa de Pós-graduação em Artes da EBA/UFMG. v.9, n.17: mai. 2019. Disponível em <https://eba.ufmg.br/revistapos> 
Vemos a paisagem passar, enquanto passamos por ela. Do carro, mesmo sem qualquer aparelho, dominamos e captamos o espaço com nosso olhar, ao mesmo tempo em que ele foge. O que apreciamos pela janela do carro é a paisagem como fenômeno efêmero.

Nossas experiências de viagens estão condicionadas à velocidade do deslocamento. Assim como a percepção da geografia foi modificada pela estrada de ferro, os voos intercontinentais e os aparelhos de acesso à internet promoveram remodelações da nossa concepção de espaço-tempo. Nesses casos, o movimento físico do deslocamento não é necessariamente uma ação dos corpos, mas uma tarefa delegada à máquina - o carro é uma dessas máquinas de deslocamento. $\mathrm{O}$ homem contemporâneo, como afirma Virilio, não é um nômade, é um passageiro. Levado de um ponto a outro, ele está cada vez mais apartado do espaço profundo. Entre as partidas e chegadas, o intervalo é cada vez mais desqualificado. Poderíamos dizer que a sensação do espaço se esvai na medida da fugacidade do tempo.

A fotografia nos revela sempre uma extensão temporal na dimensão descritiva da imagem. Muito já se disse sobre a capacidade da fotografia de fixar o instante. O instante "é precioso por não ser passível de repetição e de imitação, pelo fato de encarnar o mistério do tempo". ${ }^{4}$ Os instantes privilegiados, fixados sobre a película, foram conceituados na história da fotografia como "instantes decisivos", pois elevam à presença imutável a essência contingente e transitória do agora.

No conjunto das Paisagens do asfalto, é diferente a tentativa de inscrever o tempo na imagem. A duração é registrada como rastro e ruído. As imagens restituem um vestígio, por vezes ilegível como memória do tempo experimentado. Todavia a velocidade fixada na imagem, em sua nebulosidade, é também a rapidez do esquecimento como efemeridade da memória. Então, cada fotografia isoladamente, mesmo que de modo truncado, diz do movimento, da passagem do tempo e do que se perde na memória do trajeto.

RAUSCHER, Beatriz Basile da Silva. A paisagem na perspectiva tempo-espaço-máquina. PóS:Revista do Programa de Pós-graduação em Artes da EBA/UFMG. v.9, n.17: mai. 2019. Disponivel em <https://eba.ufmg.br/revistapos> 
O recurso do diaporama, presente em alguns trabalhos, coloca em sequência esses vários instantâneos arrastados no espaço. As séries ou sequências, nada mais são que paliativos para inscrever o tempo na imagem fixa.

"O que se passa com as séries, do ponto de vista do tempo?", pergunta Jacques Aumont. Suas respostas convergem com os interesses aqui colocados. Dizem respeito à nossa compreensão de que várias tomadas de uma mesma cena produz micronarrativas. Nesse caso, as narrativas das viagens que descrevem: as margens das rodovias, as paisagens degradadas, o calor, a monotonia, o silêncio.

Outro aspecto que se produz por imagens sequenciadas é o efeito de diferença, segundo Aumont: "um efeito cognitivo, quase consciente, que consiste na reconstrução, pelo espectador, daquilo que 'falta' entre as imagens". 5 Tais ideias trazem o próprio fundamento de toda percepção e o interesse reside no aspecto temporário dessas reconstruções. Essa distância entre uma imagem e outra, entre duas vistas, nos leva a uma forma de duração que se produz justamente lá "onde não há nada, nada de visível". ${ }^{6}$ Ela se ligaria, portanto, na intermitência aos tempos plenos, ou à plenitude significante.

Os intervalos e eclipses, nesses trabalhos, são decorrentes dos artifícios da técnica, para através da dilatação do tempo inscrito na imagem, resistir à efemeridade do visível. A sensibilidade expressa nessas fotografias borradas, arrastadas e em sequências interrompidas, converge com inquietações críticas, à paisagem natural e sua impossibilidade de representação.

\section{Máquinas de deslocamento: de volta ao futurismo}

Nós buscamos a essência interior das coisas: o movimento puro, e preferimos tudo em movimento, pois, neste estado, as coisas, desmaterializam-se, idealizam-se, apesar de conservarem em profundidade um forte esqueleto de verdade (BRAGAGLIA, $1980 \mathrm{p}$. 70).

RAUSCHER, Beatriz Basile da Silva. A paisagem na perspectiva tempo-espaço-máquina. 
Os dispositivos técnicos alteram a nossa visão do mundo. A percepção do mundo se transforma, com a ciência e a técnica. Assim, as paisagens se oferecem de maneiras renovadas, a partir de mudanças do modo no qual o homem, munido de seus aparelhos, se desloca no espaço. A fotografia tem papel preponderante na conjugação técnica e poética.

Sabemos que a consciência do espaço e do tempo alterou-se de modo significativo com o desenvolvimento das técnicas e máquinas. Philippe Dubois aponta que foram preponderantes, nesse processo (de 1914 até meados de 1929), o armamento, a aviação e os instrumentos óticos. A percepção, concepção e representação de um 'novo espaço', componente central da abstração suprematista, tudo isso está "vinculado a um gênero fotográfico preciso: a fotografia aérea (ou seu inverso: 'antiaérea')". ${ }^{7}$ As vistas aéreas interessaram aos pioneiros da abstração, por exibirem paisagens terrestres transformadas, sem horizonte, nem profundidade. O importante nessa visão é que ela define outro modo de “percepção e de representação do espaço, que não o herdado da perspectiva monocular clássica, isto é, um novo tipo de relação entre o sujeito e o mundo". ${ }^{8}$
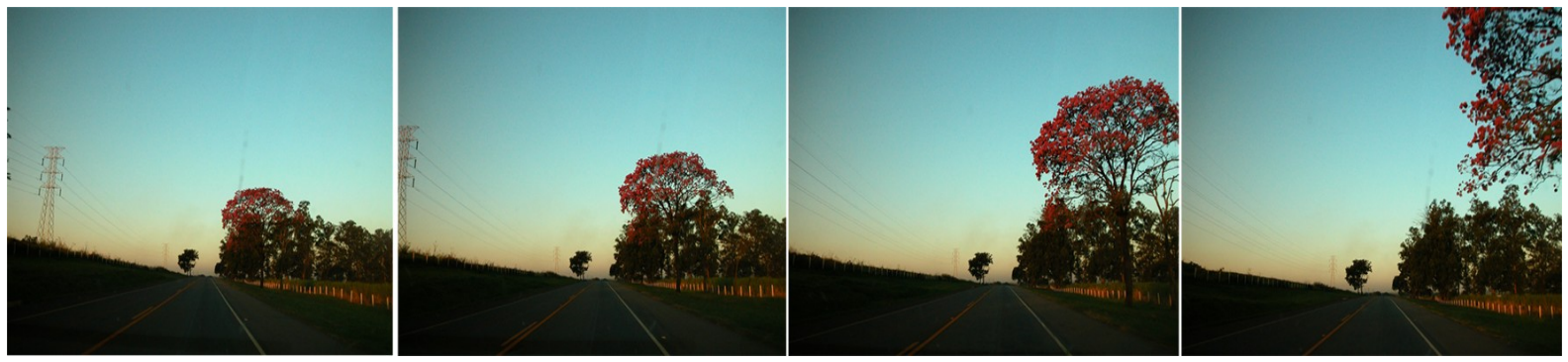

Imagem 4 - Máquinas de deslocamento (frames) - 2010

Nota: da série "Paisagens do Asfalto", vídeo interativo, 2010.

Fonte: nossa autoria.

RAUSCHER, Beatriz Basile da Silva. A paisagem na perspectiva tempo-espaço-máquina. PóS:Revista do Programa de Pós-graduação em Artes da EBA/UFMG. v.9, n.17: mai. 2019. Disponivel em <https://eba.ufmg.br/revistapos> 
Do mesmo modo que os abstracionistas se valeram das fotografias aéreas como base de noções plásticas e teóricas do espaço - também os futuristas colocaram em questão a representação tradicional, regida pela estrutura ortogonal petrificada e rigorosa. Interessados no tempo traduzido em espaço, tomaram como a matéria de sua visão, antes que o movimento, a própria trajetória.

Tendo como principais marcas a simultaneidade, a velocidade e a visão otimista do futuro e do progresso, os futuristas encontram na fotografia, mais exatamente no que chamaram de Fotodinâmica, a possibilidade do domínio sobre o espaço e o tempo por meio da técnica. Assim, a fotografia teve um importante papel no valor que o futurismo deu à técnica. Se, por um lado, rejeitaram-na em seu aspecto mimético, por outro, interessaram-se pela sua capacidade de expressar formas dinâmicas e em movimento. Assim, a fotografia se refletiu na pintura futurista. Anton Giulio Bragaglia, em seu texto Fotodinamismo futurista, de 1911, expõe a abordagem da fotografia, da qual se valem os futuristas, marcando sua diferença com a visão gerada pelas experiências da cronofotografia, de Marey, que, segundo ele, despedaça o movimento. Já a fotodinâmica, analisa e sintetiza o movimento e possui a força de recordar a continuidade do gesto no espaço. 0 valor da trajetória reside na captação daquilo que acontece no mais diminuto intervalo.

Os futuristas atribuíam ao artista a pesquisa pela representação dinâmica do real. Seu objetivo era de obter conhecimento dos "estados intermovimentais (...) e o aumento de valor estético de um corpo, arremessado (...) relativamente à luz, e as consequências de desmaterialização do movimento". ${ }^{9}$

(...) a fotodinâmica quer dar o resultado dinâmico do gesto, isto é, a síntese de trajetória (...) retratando as figuras naquela desmaterialização que nossos olhos sentem e que, portanto, nossos sentidos gozam (BRAGAGLIA, 1980 p. 69).

Essa visão do movimento, ou mesmo a visão em movimento, já era percebida na arte e na paisagem desde a instalação da ferrovia. ${ }^{10}$ Tiberghein (2001) aponta a importância da estrada de ferro no espetáculo do mundo, submetido ao domínio

RAUSCHER, Beatriz Basile da Silva. A paisagem na perspectiva tempo-espaço-máquina. PóS:Revista do Programa de Pós-graduação em Artes da EBA/UFMG. v.9, n.17: mai. 2019. Disponivel em <https://eba.ufmg.br/revistapos> 
técnico do homem. O movimento operado pelo trem, ele diz, é duplo: penetra na paisagem e, ao mesmo tempo, afasta-se dela. Explica que, como todo espetáculo supõe um afastamento, nesse caso, a rapidez necessariamente cria a distância daquilo que o passageiro do trem pode apreender quando se desloca. Na visão em movimento, os objetos imediatos são indiscerníveis, o primeiro plano desaparece e a paisagem profunda se oferece à contemplação como um panorama: isso muda nossa visão da paisagem.

O deslocamento de carro abre o espaço profundo em um corte e, assim, mergulha inteiramente o viajante na extensão da paisagem. O corpo sente os efeitos das mudanças de direção, da aceleração e desaceleração. O prazer perceptivo desse dinamismo se constitui como um dos fundamentos sensoriais da vida moderna.

O vídeo interativo Máquinas de deslocamento ${ }^{11}$ - Imagem 4, aborda as questões do tempo-espaço sob o paradigma da interatividade. Foi criado com base em uma sequência de fotografias, tomadas com o carro em movimento. O caráter digital dessas fotografias e seu processamento computacional restabelecem a sequência temporal, dando a elas o estatuto de imagem em movimento; movimento esse truncado pela interpolação de imagens como sucessão de planos.

Diferentemente das fotografias impressas da mesma série - Imagens 1, 2 e 3, em Maquinas, a imagem habita um espaço virtual: espaço que existe apenas em potência e, portanto, passível de atualização, ou seja, a imagem é a virtualidade manifestada no espaço computacional. Estando em um espaço virtual, o trabalho nos permite requisitar da máquina as instruções postas no programa e, desse modo, ele se oferece à interatividade. Podemos, no contato com a obra, acelerar ou retardar a experiência do deslocamento e do trajeto.

O computador e o carro são as principais máquinas da contemporaneidade; potentes em promover deslocamentos físicos e virtuais. O carro é, por excelência, a máquina do século 20 , enquanto o computador é a máquina do século 21, ambas alteraram significativamente a visão e experiência que temos do

RAUSCHER, Beatriz Basile da Silva. A paisagem na perspectiva tempo-espaço-máquina.

PóS:Revista do Programa de Pós-graduação em Artes da EBA/UFMG. v.9, n.17: mai. 2019.

Disponivel em <https://eba.ufmg.br/revistapos>

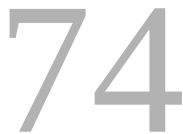


mundo. Este trabalho só foi possível por recorrer a essas máquinas. Finalizado, ele se apresenta como uma vídeo-projeção interativa. Outro de seus modos de oferecimento, que não se atrela a um lugar ou tempo determinados, é quando acessado pela rede mundial de computadores, na qual ele existe entre os objetos disponíveis da cultura digital.

É a fusão desses modos de deslocamento que o trabalho pretende acessar, pois o espaço computacional é virtual, interativo e, a priori, instantâneo. Trata-se da experiência da viagem, reelaborada pela visualidade e interatividade, essas também mecanismos de deslocamento triviais no contexto contemporâneo.

Para Paul Virilio $(1989,1993)$, os meios de transporte e de comunicação instantâneos promovem uma redução do espaço-tempo de nosso planeta. Assim, o meio geofísico sofre da desqualificação de sua "profundidade de campo", que degrada as relações entre o homem e o seu ambiente. Para o autor, disso decorre a diminuição da espessura ótica da paisagem, resultando em uma confusão entre o horizonte aparente sobre o qual toda cena se destaca, e o horizonte profundo do nosso imaginário coletivo.
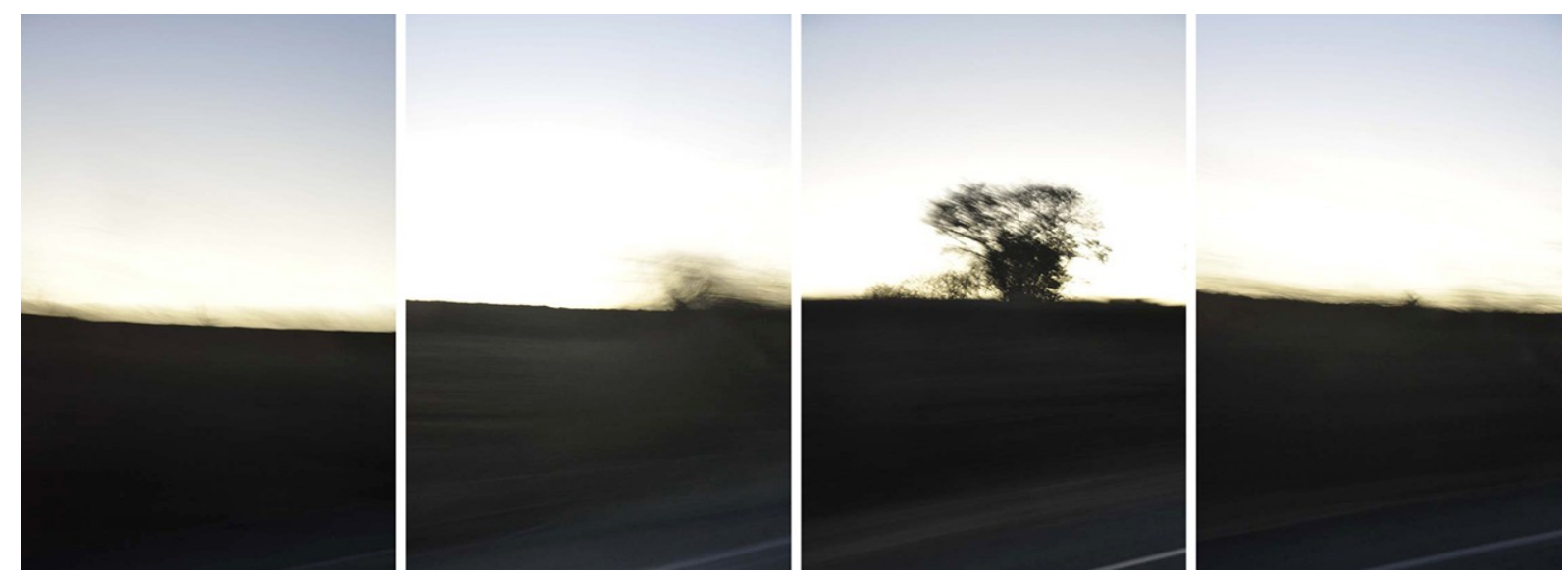

Imagem 5 - Storm

Nota: 4 fotografias (impressão em metacrilato, quatro peças), dimensão: 0,40 x 0,65 (cada) dimensão do conjunto : $160 \times 0,65,2011$.

Fonte: nossa autoria.

RAUSCHER, Beatriz Basile da Silva. A paisagem na perspectiva tempo-espaço-máquina. PÓS:Revista do Programa de Pós-graduação em Artes da EBA/UFMG. v.9, n.17: mai. 2019. Disponivel em <https://eba.ufmg.br/revistapos> 
A experiência de velocidade, tempo e trânsito que o trabalho põe em causa aciona diferentes regimes de percepção e permite questionar a duração e nosso lugar como viajantes contemporâneos, na extensão do mundo.

Podemos dizer que a simultaneidade, a velocidade e a técnica mitificadas pelo futurismo, revelam-se contemporaneamente na visão de Virilio, na "perda da narrativa do trajeto", na "confusão entre o próximo e o distante, entre o dentro e o fora", no "fim do relevo". Em oposição ao otimismo futurista, a crítica de Virilio recai sobre as tecnologias do "tempo real", que geram "o declínio dos volumes e da extensão das paisagens". ${ }^{12}$ A ação empreendida para atravessar o espaço, a ligação entre espaço e esforço, a duração e a extensão de um cansaço físico são, para ele, aquilo que empresta sua medida ao mundo da experiência sensível. A proximidade gerada pelas telecomunicações interativas, segundo sua visão, fará com que amanhã "não estejamos presentes para ninguém, encerrados em um ambiente 'geofísico' reduzido a menos que nada". ${ }^{13}$

Essa série de trabalhos com as imagens pode tocar nessas questões, quando se oferece como uma narrativa de trajeto, que resulta de um movimento físico na extensão do espaço. No entanto, sugere, por meio de uma visão embaçada e distante do real, uma crítica ao uso desqualificado desse mesmo espaço. Essas fotografias se oferecem, pois, como representação de um horizonte que pouco deixa ver, se não, um quase não ver.

\section{Fotografia como armadilha da natureza}

Ao abstrair - por um dispositivo técnico e ótico - para duas dimensões, as quatro dimensões do espaço-tempo, a perspectiva (chamada "artificial") instala entre nós o termo e a noção de paisagem. Como doutrina da representação do espaço, ela contribuiu de maneira fundamental para o modo de figurar o mundo. Assim, a perspectiva ocupou-se, em primeiro lugar, da representação das cidades e, aos poucos, deu lugar aos elementos da natureza, que terminaram por ganhar auto-

RAUSCHER, Beatriz Basile da Silva. A paisagem na perspectiva tempo-espaço-máquina. PóS:Revista do Programa de Pós-graduação em Artes da EBA/UFMG. v.9, n.17: mai. 2019. Disponivel em <https://eba.ufmg.br/revistapos> 
nomia, resultando no que chamamos de pintura de paisagem. A fotografia enquanto automatização da representação é legítima herdeira do dispositivo perspectivista. Todavia, em sua aparente objetividade, é tão simbólica como são todas as imagens. O sentido conceitual, a despeito do realismo promovido pelo sistema da perspectiva, surge quando as imagens técnicas são decifradas como tal.

Nessa reflexão, perspectiva e fotografia interessam pelo modo que se valem da técnica para contribuir e modificar nosso habitus perceptivo, impondo modelos comuns de visão, unificadores e uniformemente partilháveis. Aqui nos interessou a visão da natureza, oferecida no enquadramento conceitual da paisagem.

A série de trabalhos Paisagens do asfalto, por ter origem em imagens fotográficas, traz, implicitamente, o traço do transitório e do fugaz: presença afirmando ausência. Dubois nos explica que é essa a força que trabalha subterrânea na fotografia, ${ }^{14}$ na qual tudo converge para nos remeter fatalmente à ideia de morte do modelo. Assim são essas paisagens: artificiais, fugazes, pouco nítidas e quase mortas.

As Paisagens do asfalto revelam a representação da natureza no seu limite. Elas são a visão de lugares que foram objetos de tantas interferências, que nos levam a indagar se não estaríamos, cada vez mais, distantes do mundo natural. Assim, a paisagem da qual esse grupo de trabalhos é objeto, não é a natureza idealizada que constitui nosso imaginário, ${ }^{15}$ mas o que restou dela: uma paisagem desencantada.

A questão que finalmente se coloca: haveria ainda algo a contribuir para o discurso sensível da natureza?

A imagem da paisagem, aqui, tem na arte sua grande aliada. Isto se dá porque estamos presos às armadilhas do código: nossas construções intelectuais e nossos modos de ver. O gesto produtor de imagens não se sustenta apenas com as visões que o artista tem do mundo, "mas igualmente, com a visão que o produtor tem de imagens feitas anteriormente". ${ }^{16}$ Flusser (2008) chama a

RAUSCHER, Beatriz Basile da Silva. A paisagem na perspectiva tempo-espaço-máquina. 
atenção para o fato de que toda imagem insere-se na correnteza das imagens, pois é resultado da codificação simbólica, fundada sobre o código estabelecido. Do mesmo modo, ao tratar da paisagem, Anne Cauquelin mostra que a natureza permanece visível sob a forma de "um quadro". A paisagem, inteiramente submetida às convenções pictóricas, dá a forma e a medida das nossas percepções. Ela nos é dada pelo artifício da técnica: "quadro, forma, tela, como se queira, armadilha onde se cativa a natureza". ${ }^{17}$ Assim, a técnica ao mesmo tempo em que modifica nossa sensibilidade, dá ao artista meios plásticos originais para manifestá-la.

Nesses trabalhos, está colocada em evidência, pela fotografia, a artificialidade dessa construção: "fotografias são imagens de conceitos, são conceitos transcodificados em cenas". ${ }^{18}$ Aqui, as fotografias insistem em não nos deixar esquecer que não são o objeto nem seu duplo. A fotografia, imagem "amputada do real", sublinha, antes que anula, o caráter de artifício daquilo que foi registrado.

Para Vilém Flusser (2008), são as novas imagens, inseridas na correnteza da tradição, que podem contribuir para que a visão da sociedade se altere. Assim, espero que esta produção em andamento, que é tributária dos dispositivos técnicos digitais de captação e processamento de imagens, corresponda à seguinte proposição de Flusser: “as novas imagens não são apenas modelos para futuros produtores de imagens, mas são, mais significativamente, modelos para a futura experiência, para a valoração, para o conhecimento e para a ação da sociedade". ${ }^{19}$

Desse modo, a relação da arte com a natureza, que está impregnada de sua dimensão social, é técnica e historicamente determinada. A paisagem, por sua vez, é signo da inscrição do homem na natureza, é representação codificada, artificialmente mediada e aberta a novas abordagens; assim, sempre um lugar de partida para nossas imaginações.

RAUSCHER, Beatriz Basile da Silva. A paisagem na perspectiva tempo-espaço-máquina. PóS:Revista do Programa de Pós-graduação em Artes da EBA/UFMG. v.9, n.17: mai. 2019. Disponivel em <https://eba.ufmg.br/revistapos> 


\section{REFERÊNCIAS}

AUMONT, Jacques. O olho interminável [cinema e pintura]. (Trad.: Eloísa Araújo Ribeiro). São Paulo: Cosac Naify, 2004.

BRAGAGLIA, Anton G. Fotodinamismo futurista (1911). In: BERNARDINI, Aurora Fornoni (Org.). O futurismo italiano. Manifestos. São Paulo: Perspectiva, 1980.

CAUQUELIN, Anne. A invenção da paisagem. (Trad.: Marcos Marciolino) São Paulo: Martins Fontes, 2007.

DUBOIS, Philippe. 0 ato fotográfico e outros ensaios. (Trad.: Marina Appenzeller) Campinas, SP: Papirus, 1993.

FLUSSER, Vilém. Filosofia da caixa preta. Ensaios para uma futura filosofia da fotografia. Rio de Janeiro: Relume Dumará, 2002. 2008.

O universo das imagens técnicas: elogio da superficialidade. São Paulo: Annablume,

SANTOS, Milton. A Natureza do Espaço. Técnica e Tempo. Razão e Emoção. São Paulo: Editora da Universidade de São Paulo, 2009.

TIBERGHIEN, Gilles A. Nature, Art, Paysage. Actes Sud / École Nationale Supérieu du Paysage, 2001.

VIRILIO, Paul. O Espaço Crítico e as Perspectivas do Tempo Real. (Trad.: Paulo Roberto Pires). Rio de Janeiro: Ed. 34, 1993.

In: SALLES João M.; PEIXOTO, Nelson B. America: depoimentos. São Paulo:

Companhia das Letras; Rio de Janeiro: Videofilmes, 1989.

RAUSCHER, Beatriz Basile da Silva. A paisagem na perspectiva tempo-espaço-máquina.

PóS:Revista do Programa de Pós-graduação em Artes da EBA/UFMG. v.9, n.17: mai. 2019.

Disponivel em <https://eba.ufmg.br/revistapos> 


\section{NOTAS}

1 SANTOS, 2009, p. 103.

2 TIBERGHIEN, 2001, p. 29.

3 VIRILIO, 1989, p. 139.

4 AUMONT, 2004. p. 92.

5 Idem, p. 95.

$6 \quad$ Ibidem, p. 97.

7 DUBOIS, 1993, p. 258.

8 Idem, p. 261-262.

9 Ibidem, p. 68.

10 Ver "Rain, Steam and Speed - The Great Western Railway", 1844, de William Turner (National Gallery, Londres).

11 Trabalho realizado em coautoria com Douglas de Paula.

12 VIRILIO, 1993, p.109.

13 Idem, p.118.

14 DUBOIS, 1993, p. 81.

15 Exaltada e qualificada como exuberante, natureza e as matas do Brasil preenchem o imaginário que construímos coletivamente.

16 FLUSSER, 2008, p. 20.

17 CAUQUELIN, 2007, p. 81.

18 FLUSSER, 2002, p. 32.

19 FLUSSER, 2008, p. 21. 